\title{
MEASURING SPACE-TIME ACCESSIBILITY TO URBAN OPPORTUNITIES: A STUDY ON DEMAND FOR AND SUPPLY OF ACTIVITIES PERFORMED BY UNIVERSITY TEACHERS AND STUDENTS OF KHULNA CITY
}

\author{
K.R. RAHAMAN ${ }^{1}$, S.J. AHMED ${ }^{1} \&$ M.S. ISLAM ${ }^{2}$ \\ ${ }^{1}$ Assistant Professor and ${ }^{2}$ Lecturer, Urban and Rural Planning Discipline, Khulna University, Khulna, Bangladesh.
}

\begin{abstract}
People participate in various activity places leading their livelihood pattern (raising family, working, shopping, recreation, socializing, etc.) to have services/opportunities in their reach. Activity in urban opportunity places requires space and time, which in turn are subject to accessibility of those opportunity places. An activitybased approach within time geographical framework can explain how accessible the opportunity places are, considering space (travel barrier) and time (limited time) constraints. This study uses two checks to measure the accessibility of an opportunity: first, whether the opportunity place is within the Daily Potential Path Area (DPPA) of a participant; and second, whether the participant's activity reach time is within the opportunity opening hours. Potential Path Area (PPA) delimits a geographical area containing all feasible routes and urban opportunities given the space time constraints determined by the particular pair of fixed out of home activities, and then DPPA is prepared with the aggregation of all individual PPAs in a day. This study presents accessibility level of 10 major urban opportunity places, which are selected based on the frequency of participation performed by the university teachers and students of Khulna. This paper concludes by explaining the usefulness of the activity-based approach used in this study in accessibility studies over conventional accessibility measuring approaches.

Keywords: GIS, Khulna City, space-time accessibility, urban opportunities.
\end{abstract}

\section{INTRODUCTION}

Human beings have activities to lead their livelihood pattern. The activities that commonly continue with our lives are raising family, working, shopping, recreation and socializing [1]. An urban setting provides urban people facilities in which people can have all their activities to lead their livelihood. Miller [2] stated that, these activities require time and space, which occur at few geographical locations and for limited temporal durations. People have limited time and resources, to participate in activities like required (e.g., work, home) activities and/or desired (e.g., recreational, social) activities.

Physical accessibility is a measurement of opportunities available to people in a geographical region [3]. People need to participate in urban opportunities in specified geographical locations [4, 5]. To measure how accessible the geographical locations are, there have been conventional accessibility measures, which suffer from some limitations as these are based on locational proximity calculation of opportunities with respect to a referenced location [6]. Such measures ignore individual time budget to participate in an activity and fail to explain accessibility level of neighboring activities [7-9]. Chen [10] stated strength of activity-based approaches explaining shortcomings of traditional measures. There are four such shortcomings: one, conventional accessibility measures have only concern for home based measurements; two, such measures calculate distance based on average or zonal measures; three, traditional measures ignore focusing individual behavioral aspect in the measurements; and four, complex travel behavior of different individuals cannot be understood from conventional accessibility measures. Hence, conventional measures are not out of question in terms of sustainability, addressing demand for and supply of activities people perform. Chen [10] mentioned activity diary based accessibility as "constraint based approach" and stated accessibility benefit measures are constructed based on different assumptions about how individuals evaluate the 
opportunities available to them. He explained the strength of time-geographic concept originated by Hägerstrand [11] and formulated by Burns [12] to measure activity-based accessibility.

An activity can be defined as a physical engagement of an individual in a geographical space to satisfy his/her or/and family needs [13, 14]. Jovicic [14] stated that activities are motivated by economic, physiological and sociological needs of an individual. He mentioned that activity occurrence is a complex interaction and the interaction is the attraction is factor of

- household and individual roles and responsibilities;

- a particular life style of an individual;

- options on activity type, location and duration; and

- time, space and budget constraints.

Again, according to Axhausen [15], activity-based analysis of travel and activity participation is the attempt to address the complexity of the travelers' daily and long-term scheduling of their activity demands. Time-geographical framework can address all these issues as indicators of accessibility [16].

This study is an activity-based approach that aims at developing an algorithm to measure accessibility of major urban opportunity places performed in by university teachers and students of Khulna using their 2-day (a weekday and a weekend day) activity diary data. This study focuses on major urban opportunities identified based on frequency of activity participation. Individuals have their participation in various opportunities in their 24-h long activity pattern. Activity pattern of each individual formulates a space-time prism, which in turn defines the threshold geographical space with time constraints to measure accessibility. This study develops a time geographic algorithm, which can measure accessibility of urban opportunities situated in fixed locations of an urban setting.

\section{CONTEXTS}

There are four universities in Khulna district, two public and two private, which have their ongoing regular Undergraduate and Masters Degree courses. The private Universities are within the City boundary having no residential provisions either for the students or for the teachers. Though the students and teachers of these two universities (Northern University and Asian University) have no residential facilities, situating in the middle of the City they can consume all the urban services and opportunities in their vicinity easily. The problem exists for that of the public universities situated in the periphery of the City. One is in the southwestern periphery (Khulna University - KU) and another (Khulna University of Engineering and Technology - KUET) is in the north western periphery of the City. Both Universities have their own provision of limited seats in the University provided halls, limited recreation facilities, limited Medicare facilities, food facilities, post office facility, bank facility and such other facilities (Direct Observation Survey, 2006). And for having limited seats in the halls, all the remaining students have their residential location within the City in reach of urban facilities. The distance of CBD from KU is about $4 \mathrm{~km}$ and this long distance hinders KU teachers and students to have a number of urban opportunities, which in turn, compel them to choose their residential location within the city. On the other hand, KUET is more than $10 \mathrm{~km}$ away from the CBD and more than two-third students of KUET have provision to have their seats in University provided residential Halls. The remaining students of KUET have their residence outside the city in the neighboring area of KUET. Very few teachers of KU have their residence within the University, most of them have their residences in different places within the city. But for KUET, most of the teachers have their residence within the KUET complex. 
So there exists a greater mismatch between demand for and supply of housing for teachers and students of the public universities in Khulna. Other than residence, these people have to rely on many other urban facilities, which are located in the CBD. Considering these issues, this study explores how accessible the urban opportunity places is to this group of people.

\section{KEY CONCEPTS}

Two central time geographical concepts are the space-time path and prism. The space-time path traces the individual's physical movement in space with respect to time. The path highlights the constraining effects of a person's need to be at different locations at different times. It also highlights the role of transportation in mitigating these constraints. The space-time prism delimits the possible locations for the space-time path $[11,17]$.

Time geographical framework is a "constraint-based approach" given the defining role that spatial and temporal constraints in the formulation. In this framework, space is typically expressed as a twodimension plane, while time is depicted via a third, vertical axis. Within this three-dimensional space, the so-called time-space prisms define the limits of what is accessible [10].

Activities of an individual differ with respect to their flexibility in space and time. Fixed activities refer to events that are relatively difficult to reschedule or relocate (e.g., job). Flexible activities are relatively easy to reschedule and relocate (e.g., shop). A person has a limited time budget or available time to allocate among flexible activities. The area, which delimits a geographical area containing all feasible routes and urban opportunities, given the space-time constraints determined by the particular pair of fixed out-of-home activities, is termed as Potential Path Area (PPA). A person cannot participate in an activity unless its location falls within the PPA (ignoring the temporal duration of activities) [6]. And then Daily Potential Path Area (DPPA) can be prepared with the aggregation all individual PPAs in a day [1].

Ohmori et al. [18] described about data from opportunity sides. They stated that opportunity data consist of location and opening hours of activity opportunities. They explored opening hours to use as temporal constraints for specifying feasible activity-travel patterns in a prism determined by activity schedules.

\section{ACCESSIBILITY ALGORITHM}

\subsection{Determination of DPPA}

The Algorithm searches for the feasible routes and feasible areas based on time budget of an individual and thus demarcates DPPA. It searches centering a fixed activity point. On the transport network it addresses the nearest node from the activity point as the center of the search.

If an individual has a particular time budget and a particular travel mode with a particular travel speed, then that individual also has a limited distance he/she can travel. This limited distance is for the time constraint. Again he/she cannot travel a equal Euclidean distance from a center because the transport network is not linear on each side from a particular center in practice, which is the space constraint.

The Algorithm developed in this study determines the limited travel distance and allocates among network arcs up to the limit centering the fixed activity point, from the total amount of arcs available in the transport network. Then, it demarcates the possible locations for these limited distant arcs. The location so demarcated is defined as PPA for a fixed activity. All such locations of all PPAs in a day ultimately are aggregated and so demarcated DPPA (Figs. 1 and 2). Then spatial search is performed for opportunity points that are within the DPPA.The search results frequency of points 


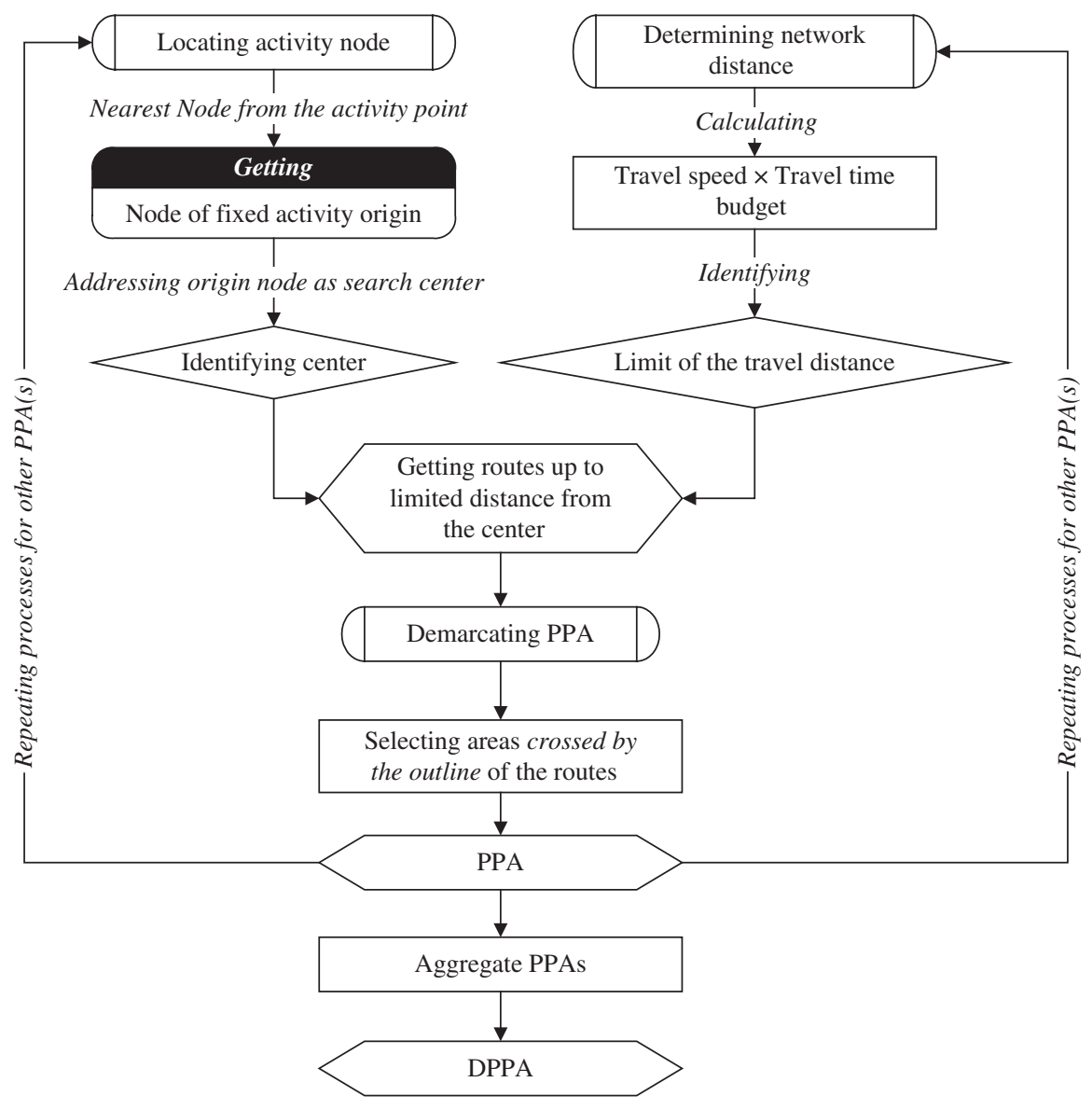

Figure 1: Operationalization of the algorithm to delimit DPPA.

that are contained by the DPPAs. The higher the amount of individual DPPA are contained in an opportunity location, the higher the degree of accessibility of that opportunity location is. This study is based on the activity diary data of individuals, which defines the degree of accessibility of an opportunity location.

\subsection{Accessibility checks}

To measure accessibility of opportunities, this study suggests two checks, one for DPPA and another for opening hours of the opportunities (Fig. 3). In the first check, it takes decision whether an opportunity location is within the DPPA, and in the second, whether individual's travel end time is within the opportunity opening hours. If the answers of the both checks are "Yes," then the individual is said to be accessible for that opportunity and if any check of the two checks answers "No," the individual is said to be not accessible for that opportunity. Finally, it is counted for each opportunity location, how many individuals are accessible for an opportunity location, which in turn infers accessibility of an opportunity: how accessible an urban opportunity place is. 


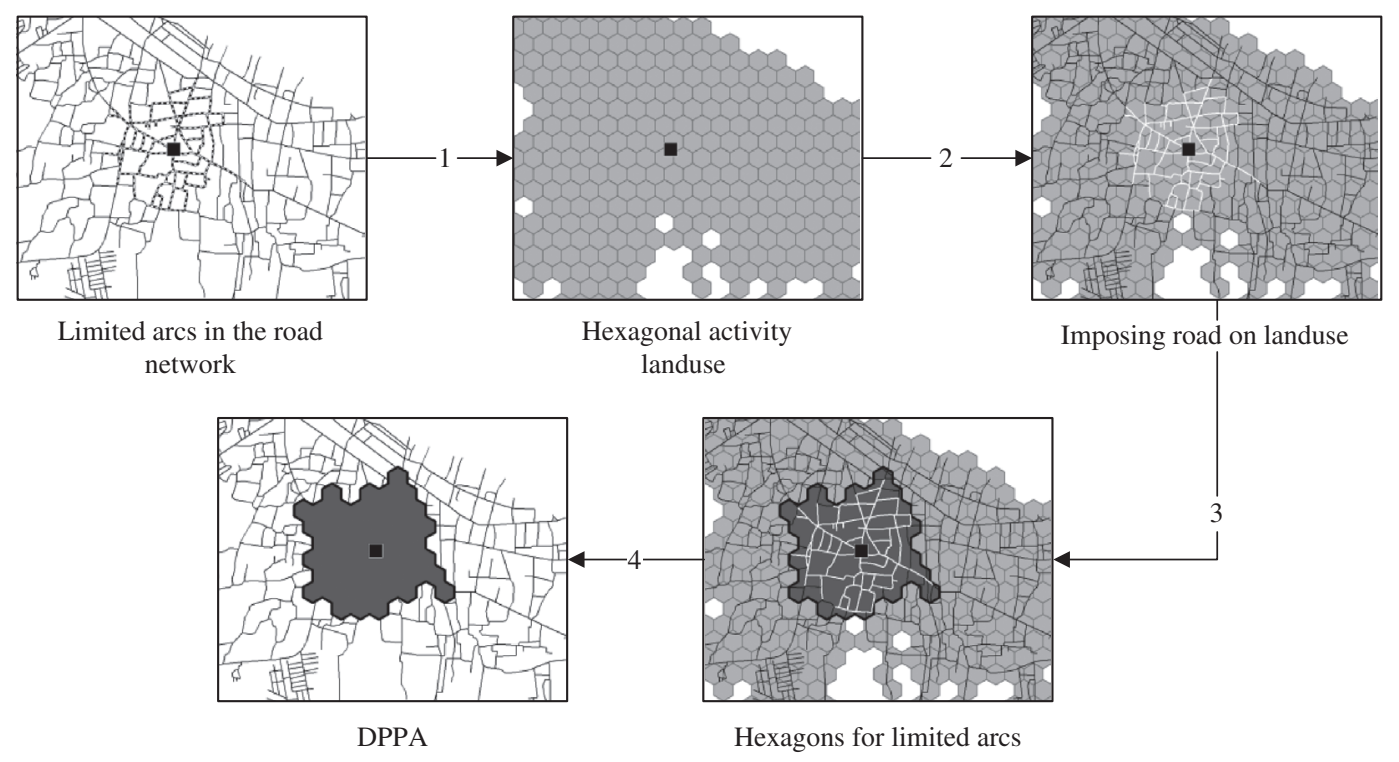

Figure 2: Steps of DPPA preparation (schematically).

\subsection{How sustainable the proposed algorithm is?}

The Algorithm developed in this study measures accessibility based on activity/activities performed by individuals in spatial locations, not based on the supply side data of spatial locations. This notion focuses on the strength of realization of mobility concept. The proposed algorithm can handle the sense of mobility interrelating with the idea of accessibility. Mobility has difference in its definition with that of accessibility. Mobility is meant for the degree of frequency people participate in activities. Mobility is a societal phenomenon depends on differential characteristic pattern of individuals [19]. Mobility can be understood and explained under time geographical framework as it has concern for individual activity details. The concept of fixed activity points as the trajectories of DPPA is based on the notion that individual activities are constrained by the space-time behavior of people's mandatory activities [20]. And people get accessibility to mandatory activity places for the reason they want themselves having mobility in those places [21]. Mobility can be explained by activity-based approach where activity is defined as a physical engagement of an individual in a geographical space to satisfy his/her or/and family needs [13,14]. This algorithm addresses activity diary as the indicator of accessibility, which is useful for synthesizing activity-travel data and replicating activity-travel patterns to measure accessibility.

The algorithm can very friendly be used for explaining activity pattern and accessibility pattern of large datasets of large urban settings. Accessibility to various urban opportunities and various urban activity places of a large number of individuals can be handled using this Algorithm, which in turn would assist in the field of activity planning. Residential clusters of and/or similar activity groups in large urban settings can be addressed thereby in terms of explanation of accessibility pattern.

This algorithm can be replicated in the studies of explaining expected traffic through travel forecasting using travel start time data from different travel nodes, pattern of travel mode usage using the data of modal availability, traffic congestion using the data of level of service (capacity and volume) of different urban roads, and so on. 


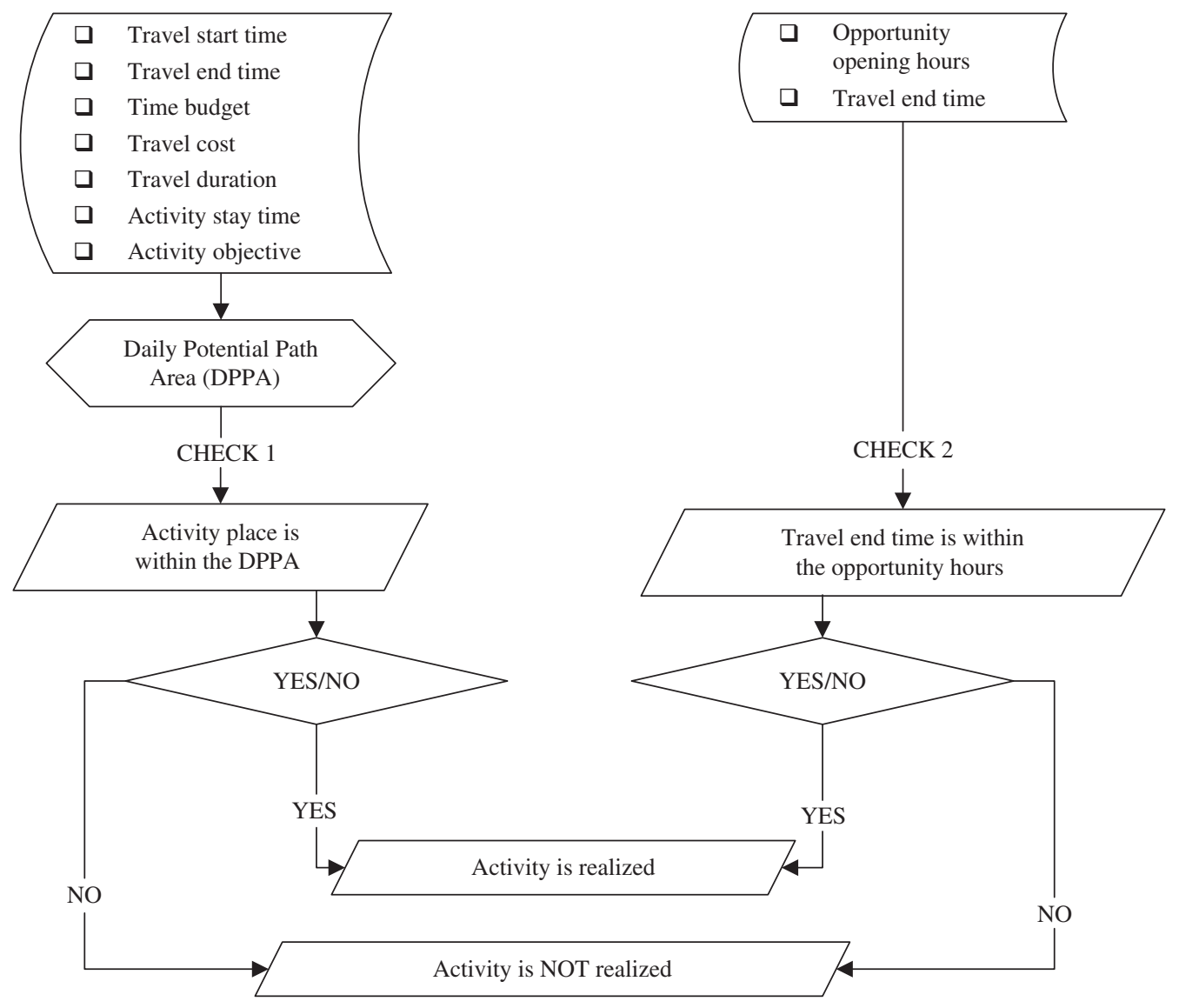

Figure 3: Accessibility checks in the algoritham.

\section{DATA AND DEFINITION OF OPPORTUNITY PLACES}

Five types of data are required for this study. Those are activity diary data, digital road network data, digital urban opportunity location data, digital land use data and opening hours' schedule of urban opportunity places for the operationalization of the accessibility algorithm. The activity diary data has been collected from individuals based on questionnaire survey from teachers and students and some of the activity places' opening hours data are collected from institutional interview from institutional personnel. Except these, all other data are collected from the city authority (Khulna City Corporation - KCC), KU and KUET. The KU digital road network data and the KUET digital road network data are merged with and spatially adjusted based on the city road network data collected from KCC. The land use data of Khulna City is manipulated as hexagonal tessellation using FLOWMAP software (for more information, please visit also http://www.flowmap.geo.uu.nl). The centroids of hexagons can better represent the data of the same than that of grids and why hexagonal land use cluster has been chosen in this study to explain activity characteristics. According to the data collected from university individuals, $73.8 \%$ individuals choose traffic mode after a limit of walking distance, $100 \mathrm{~m}$. For other individuals, they like to have traffic mode after walking more than $100 \mathrm{~m}$. This is because the land use tessellation for hexagons is taken $100 \mathrm{~m}$ hexagon. The area of each 
hexagon is $0.02341 \mathrm{~km}^{2}\left(23,410 \mathrm{~m}^{2}\right)$, which is taken as the unit of DPPA calculation for this study. These $100 \mathrm{~m}$ hexagonal clusters are said to be activity clusters so forth in this paper.

The activity diary data of 1100 individuals (200 teachers and 900 students) of Universities of Khulna have been collected. A total of 6688 activities in a 2-day long activity day (a week day and a weekend day) have defined their activity types (Fig. 4). Among different activity types 5565 outof-home and out-of-work activities have been counted. Such activities are mainly shopping, food and grocery, medical service, recreation and personal business, which five are said to be major activities for this study and such major activities are counted 4958 (about 90\%) of 5565 out-of-work activities. This activity types are submerged according to similar spatial locations and 10 major activity locations are defined for most frequent 10 out-of-work activity places. In such major out-ofwork activity places the respondents perform 4628 activities and why these places are defined as major urban opportunity places (Tables 1 and 2). In this study, accessibility to opportunities means accessibility to out-of-work activities in particular geographical regions. This study particularly measures such accessibility to opportunities. People who are surveyed have $75 \%$ out-of-work activity in Khulna city.The undefined activities (9\% of total activities found) are those which individuals do not want to disclose and hence measuring accessibility of urban opportunities does not include undefined activities.

\section{ANALYSIS AND RESULTS}

Accessibility of urban opportunity places, defined in this study, is based on activities to urban opportunity places performed in by university teachers and students of Khulna. The sample for handling activity data to measure accessibility of urban opportunity places are not out of question for the true measure, how accessible the urban opportunity places are. It is because all these 10 major urban opportunity places are not only serving facilities for university teachers and students but include all other individuals out in the city also. The methodological development of this study, to measure activity-based accessibility of urban opportunity places is the core of this study. While choosing 1100 (200 teachers and 900 students) individuals for their activity information, there were some factors within activation: spatial variability in the meaning of residential address, caution for lesser number $(<50)$ of individuals from each bus stops (bus service provided by university authorities for teachers and students), and variability of disciplines/departments in the Universities $(<50$ individuals from a discipline). The sampled data were not rigorous for representation in terms of comparability of accessibility.

According to the algorithm developed in this study, the higher an opportunity place is contained by DPPAs, the higher the degree of accessibility of the opportunity place is. 1100 DPPAs are prepared for 1100 individuals in this study and are operationalized for the search of opportunity places within the DPPAs. The highest amount of activities among out-of-work activities of teachers and students are identified in Dakbanglo area (Table 2), but 76.6\% (the highest) DPPAs are counted that contain Nirala area, which is basically a residential area where people have their activities like; home activity, personal business and food and grocery (Table 2). Dakbanglo and New Market are two core shopping area in Khulna City where, Dakbanglo for students, and New Market for teachers is more accessible. Recreational activity is identified as more popular in student community. For recreational activities, Forest Ghat is contained by the highest DPPAs among (other than Forest Ghat, New Market, KU, KUET, Rupsha Bridge and Bhairab par) recreational places.

Activity-based accessibility also cares for the residential location of the individuals [24]. The study identifies that individuals travel more distance for out-of-work activities than for work activities. Of the sampled individuals, the average travel distance for work activity is $3.25 \mathrm{~km}$ and that for out-of work activities is $5.84 \mathrm{~km}$. The accessibility of different opportunity places is defined by the 


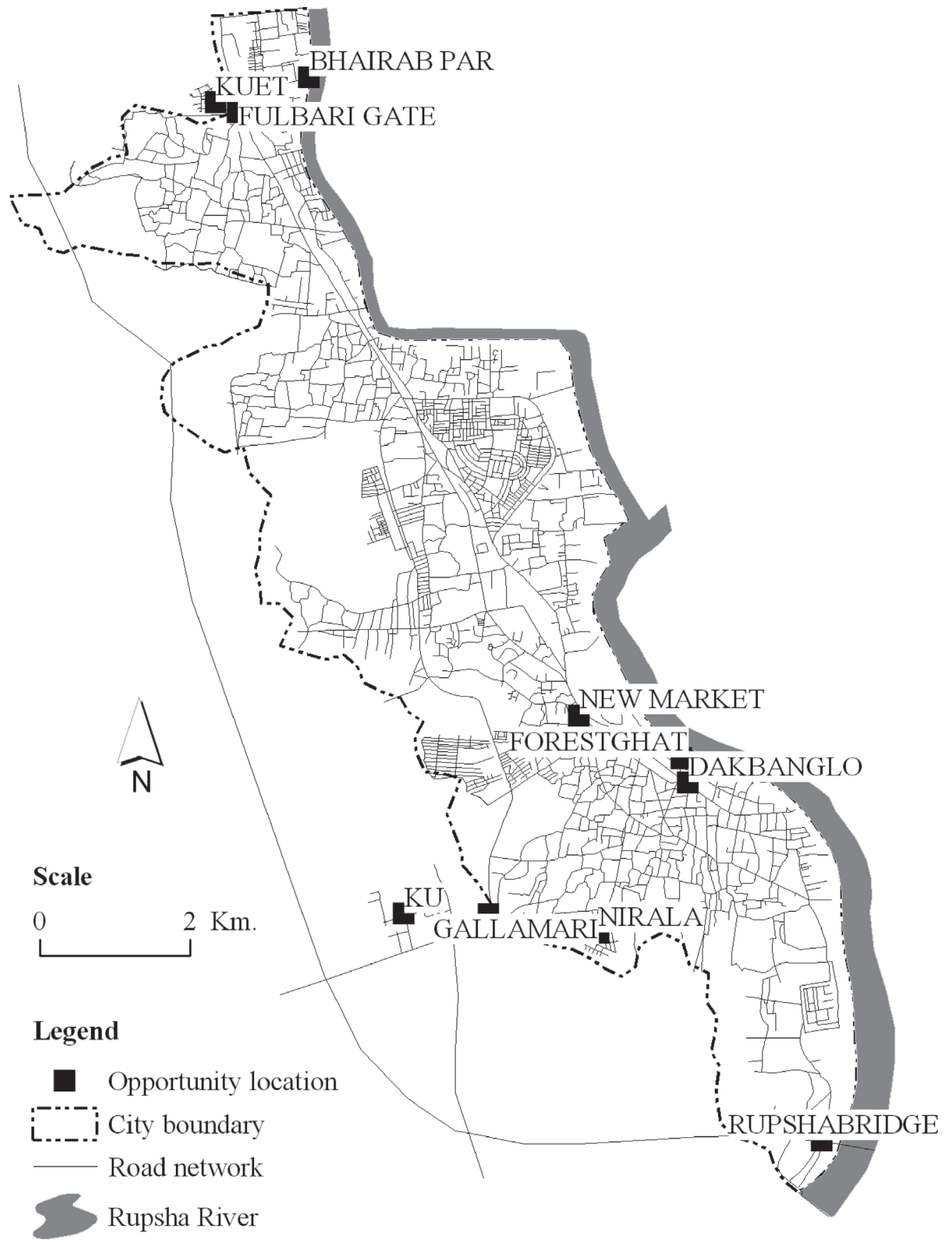

Figure 4: Major activity places performed in by university teachers and students. Source: Adapted from Urban and Rural Planning [23] and digitization of activity locations, 2006. 
Table 1: Different activity objectives and their frequency.

\begin{tabular}{lccc}
\hline Activity objective & Number & Per cent & Subtotal of per cent \\
\hline Work & 1123 & 16.8 & 16.8 \\
Shopping & 1328 & 19.9 & 74.1 \\
Food and Grocery & 779 & 11.6 & (Out-of-work activity \\
Recreation & 1896 & 28.3 & objective) \\
Medical Services & 26 & 0.4 & \\
Personal business & 929 & 13.9 & 9.1 \\
Others/undefined & 607 & 9.1 & 100.0 \\
Total & 6688 & 100.0 & \\
\hline
\end{tabular}

Source: Ref. [22].

travel distance of the individuals. This study shows an aggregate measure that, if an individual's residential location is within the average distance he/she travels for out-of-work activities from an opportunity place, that individual has accessibility to that opportunity place. The higher the activity clusters are within 5.84 network distance from an opportunity place, the higher accessible the opportunity place is. Among all the major opportunity places in Khulna for University teachers and students, New Market gets the highest activity clusters' coverage, which is more than 50\% of Khulna City area (Table 3 and Fig. 5). This aggregate approach is some sort of inclination from disaggregate individual characteristic approach but would help in understanding opportunity side accessibility that is based on activity data.

According to this study, only distance is not the indicator of accessibility because individuals' activity does not consider only distance to have an opportunity. From the sampled data, it is revealed that, Rupsha Bridge is contained by $68 \%$ individuals' DPPA, but it covers only $16 \%$ area of the city. So the accessibility is not only the question of spatial coverage, but it necessitates time and activity participation also.

Opening hours of opportunity places influence in activities of individuals. Time overlap with fixed activities upon flexible activities constrains participation in out-of-work activities. For all the universities of Khulna, opening time is 8:00 up to 17:00 and within this time, individuals have three times lesser out-of-work activities (Table 4). It is nine times higher for activities in New Market from 8:00-17:00 to 18:00-22:00. There are opportunity places like Bhairab par, which are not accessible after 19:00 and also some opportunity places where people usually do not come after 10:00, like Gollamari. Thus, this study suggests that accessibility of opportunity places has interrelationships among one another, in terms of opening hours and time of the day.

\section{DISCUSSION AND CONCLUSIONS}

Using activity-based time geographical framework to measure accessibility of opportunity places, this study infers that the opportunity side (supply) data of services cannot be the actual indicator to know how many individuals are served or are facilitated. Urban opportunity places in Khulna City have dynamic and variable use as the measure of activity objective, for example, Rupsha Bridge is being used for recreational purpose (336, $6 \%$ of total out-of-work activities performed by University teachers and students), whereas Hadis Park is a recreational site, but only five activities found in Hadis Park among 5565 out-of work activities. Activity based approach which addresses time 


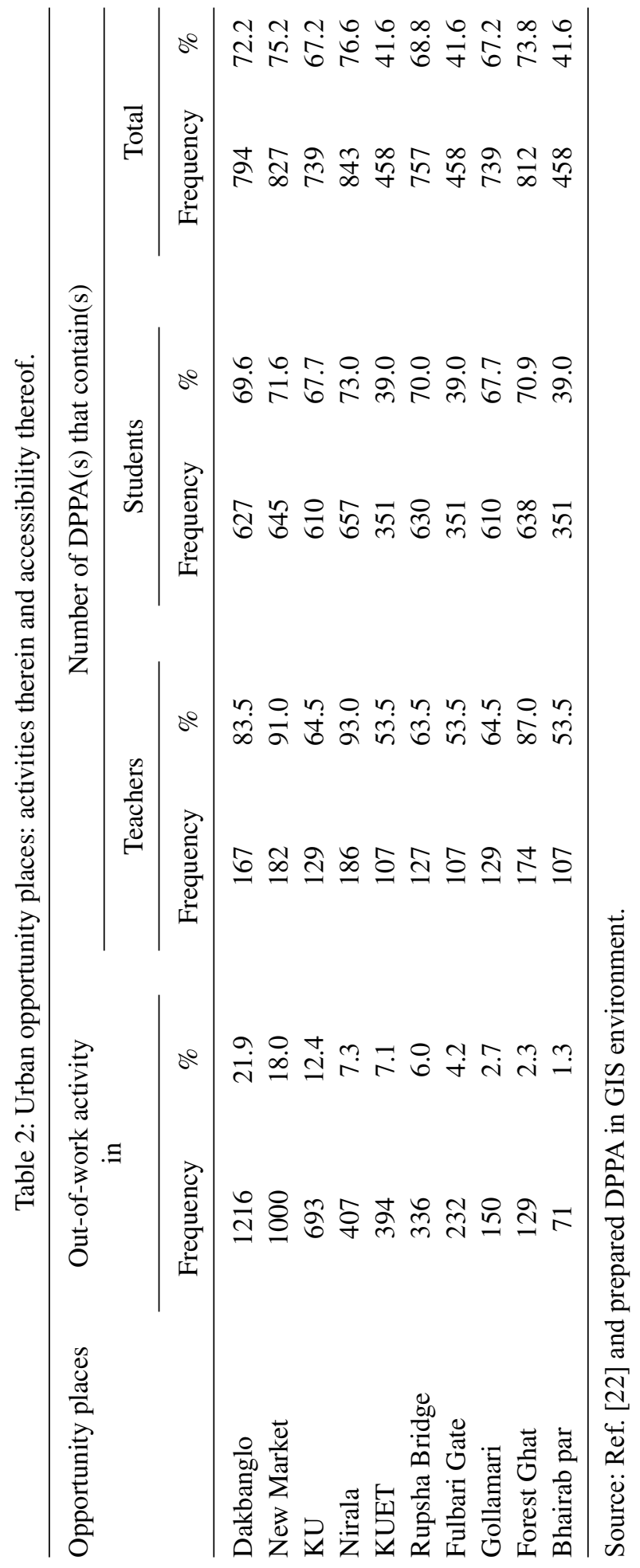


Table 3: Urban opportunity places and their accessibility.

\begin{tabular}{lrcc}
\hline Opportunity places & $\begin{array}{c}\text { Number of activity } \\
\text { cluster }\end{array}$ & $\begin{array}{c}\text { Area coverage } \\
\left(\mathrm{km}^{2}\right)\end{array}$ & $\begin{array}{c}\text { Per cent of Khulna city area } \\
\left(47.99 \mathrm{~km}^{2}\right)\end{array}$ \\
\hline Dakbanglo & 962 & 22.52 & 46.93 \\
New Market & 1105 & 25.87 & 53.91 \\
KU & 547 & 12.80 & 26.67 \\
Nirala & 756 & 17.70 & 36.88 \\
KUET & 498 & 11.66 & 24.30 \\
Rupsha Bridge & 328 & 7.68 & 16.00 \\
Fulbari gate & 574 & 13.44 & 28.01 \\
Gollamari & 826 & 19.34 & 40.30 \\
Forest Ghat & 979 & 22.92 & 47.76 \\
Bhairab par & 437 & 10.23 & 21.32
\end{tabular}

Source: Ref. [22] and prepared DPPA in GIS environment.
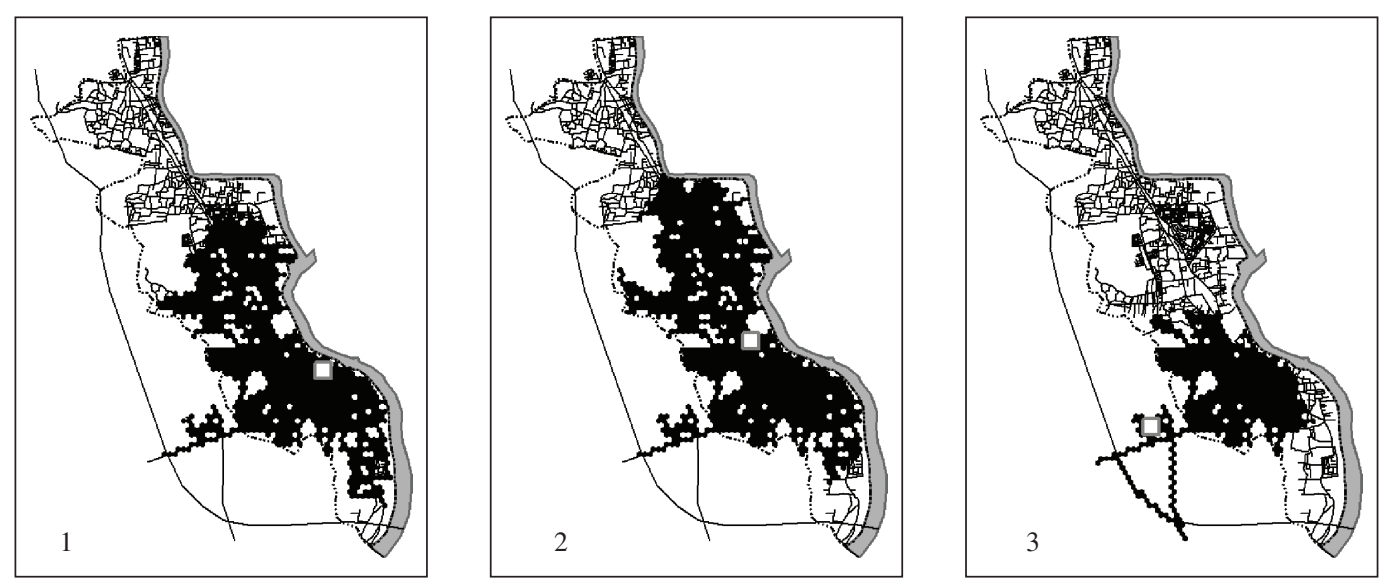

Figure 5: Coverage of activity clusters by different opportunity places. Note: 1 for Dakbanglo, 2 for New Market and 3 for KU.

constraints (time of the day, availability of time, modal speed, etc.) and space constraints (modal availability, transport network, modal choice, etc.) is helpful to measure accessibility of a prescribed service.

Secondly, this study identifies why distance is not the only indicator of accessibility. One of the distance based studies is by Oliveira and Bevan [25] who stated three methods which have been used for analyzing geographical distribution and redistribution of public facilities: spatial interaction models (SIMs), entropy models and mathematical programming models. O'Kelly [26] said SIMs are a form of probability interaction modeling and use information on population numbers, service capacity, distance and a decay function to reproduce flows of consumers. SIMs can replicate the current pattern of consumer flows between demand and residential zones. However, there are some problems identified with SIMs. First, they are inadequate in predicting user flows in response to supply changes because they assume that when there are changes in one facility all the other facilities gain in comparison 
Table 4: Accessibility of different places in different time for individuals' out-of home and out-of-work activities.

\begin{tabular}{|c|c|c|c|c|c|c|c|}
\hline \multirow{3}{*}{$\begin{array}{l}\text { Activity } \\
\text { places }\end{array}$} & \multicolumn{6}{|c|}{ Time of the day } & \multirow{3}{*}{$\begin{array}{c}\text { Comparison } \\
\text { ratio of total } \\
(8: 00-17: 00): \\
(18: 00-22: 00)= \\
1: ?\end{array}$} \\
\hline & \multicolumn{3}{|c|}{$\begin{array}{c}\text { 8:00-17:00 } \\
\text { (number of activity) }\end{array}$} & \multicolumn{3}{|c|}{$\begin{array}{c}\text { 17:00-22:00 } \\
\text { (number of activity) }\end{array}$} & \\
\hline & Teachers & Students & Total & Teachers & Students & Total & \\
\hline Dakbanglo & 22 & 107 & 129 & 177 & 910 & 1087 & 8.4 \\
\hline New Market & 46 & 56 & 102 & 120 & 778 & 898 & 8.8 \\
\hline KU & 0 & 227 & 227 & 0 & 466 & 466 & 2.1 \\
\hline Nirala & 84 & 42 & 126 & 114 & 167 & 281 & 2.2 \\
\hline KUET & 0 & 205 & 205 & 0 & 189 & 189 & 0.9 \\
\hline Rupsha & 7 & 89 & 96 & 61 & 179 & 240 & 2.5 \\
\hline \multicolumn{8}{|l|}{ Bridge } \\
\hline Fulbari gate & 55 & 44 & 99 & 32 & 101 & 133 & 1.3 \\
\hline Gollamari & 36 & 86 & 122 & 6 & 22 & 28 & 0.2 \\
\hline Forest Ghat & 0 & 28 & 28 & 7 & 94 & 101 & 3.6 \\
\hline Bhairab par & 0 & 0 & 0 & 0 & 71 & 71 & -E- (say 71) \\
\hline Total & 250 & 884 & 1134 & 517 & 2977 & 3494 & 3.0 \\
\hline
\end{tabular}

Source: Ref. [22].

with their shares of utilization prior to that change [27-29]. Secondly, SIMs do not consider either local variations from the local health system or the hierarchical and organizational structure of hospitals [25].

Thirdly, this study suggests that accessibility of opportunities is not only influenced by the opportunity side indicators (like, availability of quality services) but it is influenced by other activity options performed by individuals also. This influence can be for time schedule of all the opportunities in an urban setting for all the activities in it, or for availability of transport services to participate in a particular activity type. So, planners of opportunity places are suggested in this study so that they could have care for activity overlap and opportunity placement while they plan for activities of new opportunity places.

The algorithm developed in this study could be used successfully to determine accessibility of different group people or of different residential clusters for single or multi-number opportunity places. The dataset used in this study is not out of question in terms of how representative the sample is, but this algorithm could be user-friendly for large datasets of an entire urban setting. Survey method for data collection is an important aspect in the question of representativeness. Data are reliable only when objectives of the study meet the data collection method. This study could be replicated if data are representative in studies like transport forecasting, traffic volume estimation and capacity design, land use modeling, future direction of urban activities, service planning, location and timing of service places and so on.

\section{REFERENCES}

[1] Miller, H.J., Activities in Space and Time. Handbook of Transport 5: Transport Geography and Spatial Systems, Pergamon/Elsevier Science, 2004.

[2] Miller, H.J., What about people in geographic information science? Computers, Environment and Urban Systems, 27, pp. 447-453, 2003. 
[3] Lee, M.S. \& McNally, M.G., Measuring Physical Accessibility with Space-Time Prisms in a GIS: A Case Study of Access to Health-Care Facilities, Institute of Transportation Studies, University of California, Irvine, USA, 2002.

[4] Munshi, T. \& Brussel, M., Use of Geo-information to Determine the Work Place Accessibility Using Public Transport in Ahmedabad City, India, Department of Urban and Regional Planning and Geo-information Management, International Institute of Geo-information Science and Earth Observation, The Netherlands, 2005.

[5] Kwan, M.-P., Interactive geovisualization of activity-travel; patterns using three-dimensional geographical information systems: a methodological exploration with a large data set. Transportation Research, Part C, 8, pp. 185-203, 2000.

[6] Kwan, M.-P., Gender and individual accessibility to urban opportunities: a study using space time measures. Professional Geographers, 51(2), pp. 210-227, 1999.

[7] Kwan, M.-P., Space time and integral measures of individual accessibility: a comparative analysis using a point based framework. Geographical Analysis, 30(3), pp. 191-217, 1998.

[8] Pickup, L., Women's gender-role and its influence on their travel behavior. Built Environment, 10, pp. 61-68, 1984.

[9] Talen, E. \& Anselin, L., Assessing spatial equity: an evaluation of measures of accessibility to public playgrounds. Environment and Planning A, 30, pp. 595-613, 1998.

[10] Chen, C., An Activity-Based Approach to Accessibility, PhD Dissertation, University of California, Irvine, USA, 1996.

[11] Hägerstrand, T., What about people in regional science? Papers of the Regional Science Association, 24, pp. 7-21, 1970.

[12] Burns, L.D., Transportation, Temporal and Spatial Components of Accessibility, Lexington Books: Lexington, MA, 1979.

[13] Lee, M.S. \& McNally, M.G., Application of Space-Time Prisms for the Measurement of Accessibility, Institute of Transportation Studies, University of California, Irvine, USA, 1998.

[14] Jovicic, G., Activity Based Travel Demand Modeling: A Literature Study, Note 8, Denmarks Transport Forskning, Denmark, 2001.

[15] Axhausen, K.W., Activity-based modelling: research directions and possibilities. New Look at Multi-Modal Modelling, eds D. Simmonds \& J.J. Bates, Report for the Department of Environment, Transport and the Regions, London, 2000.

[16] Schwanen, T. \& Dijst, M., Time Windows in Workers' Activity Patterns: Empirical Evidence from The Netherlands, NECTAR Conference, Espoo, Finland, 2001.

[17] Miller, H. J., A measurement theory for time geography. Geographical Analysis, 37, pp. 17-45, 2005.

[18] Ohmori, N., et al., Simulation Model for Activity Planning (SMAP): GIS-based gaming simulation. Conference of 9th WCTR, Seoul, 2001.

[19] Ohmori, N. \& Harata, N., Evaluation of Space-Time Accessibility Considering Activity Engagement of the Elderly, The University of Tokyo, Japan, 2003.

[20] Wu, Y.-H. \& Miller, H.J., Computational tools for measuring space-time accessibility within dynamic flow transportation networks. Journal of Transportation and Statistics, 4, pp. 1-14, 2001.

[21] Arentze, T., Katoshevski, R. \& Timmermans, H., A Micro-simulation Model of Activity-Travel Behavior of Individuals in Urban environments, Urban Planning Group, Eindhoven University of Technology; The Netherlands, 2001.

[22] Activity Diary data collected from university teachers and students of Khulna City, 2006.

[23] Urban and Rural Planning Discipline, Environmental Maps and Workbooks for Khulna City, Bangladesh, Urban and Rural Planning Discipline, Khulna University, Khulna, 1999. 
[24] Stopher, P.R., et al., Synthesizing household travel survey data: application to two urban areas. 23rd Conference of Australian Institutes of Transportation Research, Sydney, Australia, 2001.

[25] Oliveira, M.D. \& Bevan, G., Improving geographic equity: location-allocation models to redistribute hospital supply. LSE Health and Social Care Discussion, Paper Number 17, The London School of Economics and Political Science, London, 2005.

[26] O'Kelly, M.E., Spatial-interaction-based location-allocation models. Spatial Analysis and Location-Allocation Models, eds A. Ghosh \& G. Rushton, Van Nostrand Reinhold Company: New York, 1987.

[27] McLafferty, S., Predicting the effect of hospital closure on hospital utilization patterns. Social Science and Medicine, 27(3), pp. 255-262, 1988.

[28] Porell, F.W. \& Adams, E.K., Hospital choice models: a review and assessment of their utility for policy impact analysis. Medical Care Research Review, 52(2), pp. 158-195, 1995.

[29] Ghaeli, R. \& Hutchinson, B.G., Spatial variation in travel behavior within Greater Toronto area. Journal of Transportation Engineering, ASCE, 124(2), pp. 179-187, 1998. 